\title{
Exploring legitimization strategies for contested uses of citizen-generated data for policy
}

\author{
Anna Berti Suman* \\ The Tilburg Institute for Law, Technology, and Society - Tilburg University (The Netherlands)
}

\section{Sven Schade}

Digital Economy Unit - European Commission, Joint Research Centre (Italy)

\author{
Yasuhito Abe \\ Faculty of Global Media Studies - Komazawa University (Japan)
}

In this article, we investigate how citizens use data they gather as a rhetorical resource for demanding environmental policy interventions and advancing environmental justice claims. While producing citizen-generated data (CGD) can be regarded as a form of 'social protest', citizens and interested institutional actors still have to 'justify' the role of lay people in producing data on environmental issues. Such actors adopt a variety of arguments to persuade public authorities to recognize CGD as a legitimate resource for policy making and regulation. So far, scant attention has been devoted to inspecting the different legitimization strategies adopted to push for institutional use of CGD. In order to fill this knowledge gap, we examine which distinctive strategies are adopted by interested actors: existing legitimization arguments are clustered, and strategies are outlined, based on a literature review and exemplary cases. We explore the conceivable effects of these strategies on targeted policy uses. Two threads emerge from the research, entailing two complementary arguments: namely that listening to CGD is a governmental obligation and that including CGD is ultimately beneficial for making environmental decisions. We conclude that the most used strategies include showing the scientific strength and contributory potential of CGD, whereas environmental rights and democracy-based strategies are still rare. We discuss why we consider this result to be problematic and outline a future research agenda.

Keywords: citizen-generated data, citizen science, environmental human rights, legitimacy, policy uptake

* We express our gratitude to the Guest Editor, Editors-in-Chief, and anonymous reviewers of this special issue of the journal for their precious feedback and suggestions, which offered us an opportunity to sharpen the piece, and to critically think about future research possibilities. A sincere thanks is owed to the Extinction Rebellion members cited in this article for having engaged in conversations with us. A special acknowledgement goes also to the colleagues at our research centres for thinking along with us on the topics discussed in this article. Part of this work was supported by the 'COST Action CA15212: Citizen Science to promote creativity, scientific literacy, and innovation throughout Europe', which funded a Short-Term Scientific Mission at the Joint Research Centre, European Commission. The finalization of this article was also conducted thanks to the support of the ongoing individual research grant from the Dutch Research Council NWO, the Rubicon fellowship n. 66202117. 


\section{INTRODUCTION}

In 2019, a number of events increased social and political perceptions that environmental issues, especially climate change, are ever more pressing and able to mobilize crowds. Among others, the Greta Thunberg phenomenon, the Extinction Rebellion $(\mathrm{XR})^{1}$ protests and the Australian bushfires received wide media exposure, shaping public opinion even beyond environmental activist circles. While both traditional and alternative media outlets have created a communication space for environmental activists and protestors, increasing numbers of people have found the gathering of data to be an avenue through which to substantiate their claims on environmental problems and to push in order to have their voices heard.

Academic literature has acknowledged that 'citizen-generated data' (hereinafter CGD) - including data generated via biodiversity citizen science and environmental pollution citizen sensing - can contribute to advancing 'environmental justice action'. ${ }^{2}$ In fact, environmental conflicts can be triggered by situations in which one party believes that they are excluded from access to necessary environmental data and information. ${ }^{3}$ Producing CGD concerning such environmental controversies does not merely embody demands of recognition, that is, lay citizens striving to be recognized as a legitimate actor in the debate without necessarily entailing the 'delegitimization' of the appointed institutions. ${ }^{4}$ Such CGD production also moves the debate 'beyond' the institutional system, calling in wider public constituencies and media actors in order to leverage the inclusion of alternative or complementary environmental discourses, imbued with values regarded as important to such actors. ${ }^{5}$ Indeed, cases of reactive citizen engagement ${ }^{6}$ have demonstrated that limiting the number of actors that can have a say in an environmental decision rarely helps in addressing complex environmental matters. ${ }^{7}$

In this context, we characterize CGD as rhetorical resources actively produced or gathered by citizens for making an argument to support environmental justice claims. ${ }^{8}$

1. 'Extinction Rebellion' <https://rebellion.earth> accessed 17 February 2020.

2. M Haklay and L Francis, 'Participatory GIS and Community-based Citizen Science for Environmental Justice Action', in JG Chakraborty and R Holifield (eds), The Routledge Handbook of Environmental Justice (Abingdon, Routledge 2018).

3. Discussions during a specialization course on the management and prevention of environmental conflicts through mediation, February 2020, held at Systasis - Centro Studi per la prevenzione e la gestione dei conflitti ambientali and Milan City Council.

4. ibid.

5. In addition to providing relevant environmental knowledge and scientific evidence, citizen science and similar practices are also a way to inject in policy- and decision-making processes values that affected communities and individuals regard as important.

6. Among the others, we can mention one of our case studies, the case of Analyze Basilicata, a challenging civic monitoring initiative that inquired into oil extraction in Basilicata $<\mathrm{https} / / /$ data-activism.net/2018/12/civic-resistance-to-environmental-failures-from-the-south-of-thenorth-the-analyzebasilicata-initiative/> accessed 24 February 2020. We engaged in discussions with the founder of the initiative at the book launch Colonia Basilicata at the European Commission Joint Research Centre, Ispra (Italy) and Milan City Council, February 2020.

7. ibid.

8. It should be noted that, although the totality of the cases that we analysed aim at protecting the environment in different ways, hypothetically citizen science could be used also 'against' the environment, using science to discard arguments advanced by environmentalists. Our analysis and conclusions would be completely different if we were to target this type of initiative. 
CGD enable lay citizens to 'question expert knowledge production through critical making tactics, and creates opportunities to generate credible public science'. 9 As such, CGD that - to variable degrees - challenge the institutional status quo can be regarded as a form of 'social protest', a term defined in the Oxford Dictionary as a 'political expression that seeks to bring about social or political change by influencing the knowledge, attitudes, and behaviours of the public or the policies of an organization or institution'. ${ }^{10}$ Numerous initiatives aimed at collecting CGD on environmental matters aim to influence the system through what we frame as social ('social change') or policy uptake ('political change'). It is this intention to change the status quo (that is, to challenge how environmental issues are traditionally framed) that makes CGD play a role in social movements as a form of real protest. Whereas some CGD initiatives deliberately oppose the institutional way of governing the environment and providing environmental information, ${ }^{11}$ other projects have a less reactive approach and strive, instead, to complement institutional environmental monitoring. ${ }^{12}$ Since protesting can function against the system and also in support of an established institutional setting, for example to counteract extremist movements that threaten the status quo, the production of CGD can be seen not just as a 'mere contradiction' of the establishment, but rather as a practice pushing for mutually beneficial changes in the management of environmental issues. Yet both the more cooperative and the more confrontational initiatives ${ }^{13}$ often have to struggle to have their claims heard and their data used in policy-making processes. Moreover, at times, governmental actors such as environmental protection agencies supporting CGD, have also had to battle to have data used for institutional purposes. ${ }^{14}$

A 2018 study launched by the European Commission on citizen science for environmental policy, based on an inventory of more than 500 initiatives producing CGD for environmental policy around the world, ${ }^{15}$ clearly shows how some CGD initiatives use their data as 'mere' scientific evidence to influence policy. ${ }^{16}$ The study also illustrates that other initiatives embed these data with values and use them to

9. SA Wylie et al., 'Institutions for Civic Technoscience: How Critical Making is Transforming Environmental Research' (2014) 30(2) Information Society Quarterly 181.

10. 'Social Protest' by Oxford Bibliographies <https://www.oxfordbibliographies.com/view/ document/obo-9780199756841/obo-9780199756841-0005.xml> accessed 5 February 2020. 'Protest' by Oxford Advanced Learner's Dictionary <https://www.oxfordlearnersdictionaries. com/definition/english/protest_1?q=protest $>$ accessed 15 February 2020. Whereas the Oxford Dictionary defines protest as 'the expression of strong disagreement', we understand social protest as not necessarily antagonistic to the institutional setting.

11. C Kullenberg, 'Citizen Science as Resistance: Crossing the Boundary Between Reference and Representation' (2015) 1(1) Journal of Resistance Studies 50.

12. S Schade et al., 'Joint Statement on New Opportunities for Air Quality Sensing - Lowercost Sensors for Public Authorities and Citizen Science Initiatives' (2019) 5 Research Ideas and Outcomes e34059.

13. ibid.

14. The Global Facility for Disaster Reduction and Recovery - GFDRR, Identifying Success Factors in Crowdsourced Geographic Information Use in Government (GFDRR, Washington DC 2018).

15. 'An Inventory of Citizen Science Activities for Environmental Policies' by the European Commission Joint Research Centre <https://data.europa.eu/euodp/data/dataset/jrc-citsci-10004> accessed 15 February 2020.

16. Bio Innovation Service, Citizen Science for Environmental Policy: Development of an EU-wide Inventory and Analysis of Selected Practices (European Commission Joint Research Centre 2018). 
advocate for change. ${ }^{17}$ From a closer look at these patterns, however, some methods of producing CGD that are ostensibly 'politically neutral' also have the collateral goal of leveraging claims and voicing opinions. Overall, therefore, CGD initiatives have sought to engage with policy intervention in different ways.

Citizen science is increasingly obtaining legitimization from institutional recognition through the endorsement of civic data and methods by scientific accreditation bodies and public authorities, such as environmental protection agencies. ${ }^{18}$ Furthermore, from a legal perspective, producing CGD can be - and has been - seen as a form of 'rights in action' expressing people's claims to live in a healthy environment and to access environmental information ${ }^{19}$ through the production of (alternative/ complementary) data that could strategically serve as evidence to demonstrate environmental violations and/or misinformation. ${ }^{20}$ CGD could even embody a new right, namely a right to contribute environmental information, ${ }^{21}$ derived from a broad interpretation of the Aarhus Convention of 1998 and of the Kyiv Protocol of 2009. ${ }^{22}$ This distinctive new right has recently stimulated discussions in the citizen science arena, both as an entitlement and a claim of those citizens who - faced with a lack or insufficiency of information on a 'matter of concern' ${ }^{23}$ - produce environmental data themselves and ask to be heard by competent authorities. ${ }^{24}$ This discourse could help to legitimize CGD in policy making.

Nevertheless, even when citizens are heard, as Kennedy notes, 'a major challenge is translating findings [from CGD] to policy makers in a way that actually influences decision making' ${ }^{25}$ If this is a challenge for citizen scientists, we can more widely note that - overall - translating scientific findings into policy is always problematic given the mediating impact of political choices. ${ }^{26}$ Science (for policy) is often contested as much as is citizen science (for policy), but when lay people are the source

17. H Jones, A Guide to Monitoring and Evaluating Policy Influence (Overseas Development Institute Background Note February 2011) Figure 11, p. 2.

18. G Wyeth et al., 'The Impact of Citizen Environmental Science in the United States' (2019) 49(3) The Environmental Law Reporter; A Berti Suman, 'Between Freedom and Regulation: Investigating Community Standards for Enhancing Scientific Robustness of Citizen Science', in L Reins (ed), Regulating New Technologies in Uncertain Times (Springer-Verlag, Dordrecht 2019).

19. A Berti Suman, Sensing the Risk: In Search of the Factors Contributing to the Policy Uptake of Citizen Sensing (Doctoral Thesis, Tilburg University, Tilburg 2020).

20. The research agency Forensic Architecture, based at Goldsmiths, University of London, is expanding in this field <https://forensic-architecture.org/about/agency> accessed 20 July 2020. 21. M Balestrini, 'Beyond the Transparency Portal: Citizen Data and the Right to Contribute' (2018) ICTlogy <https://ictlogy.net/20181004-mara-balestrini-beyond-the-transparency-portalcitizen-data-and-the-right-to-contribute/> accessed 5 February 2020.

22. Convention on Access to Information, Public Participation in Decision-making and Access to Justice in Environmental Matters (25 June 1998) 38 ILM 517, with a Protocol on Pollutant Release and Transfer Registers (21 May 2003) UN Doc. MP.PP/2003/1.

23. Balestrini (n 21).

24. Captured in a blog post by A Berti Suman, 'Citizen Sensing: Towards a Right to Contribute to Environmental Information' (2020) Environmental Law Blog, Tilburg University $<$ https://blog.uvt.nl/environmentallaw/?p=443> accessed 10 July 2020.

25. E Kennedy, 'When Citizen Science Meets Science Policy', in D Cavalier and E Kennedy (eds), The Rightful Place of Science: Citizen Science (Consortium for Science, Policy \& Outcomes, Arizona State University 2016).

26. S Jasanoff, 'Contested Boundaries in Policy-relevant Science' (1987) 17(2) Social Studies of Science 195. 
of scientific data, the process can become even more contested. In other words, the tension between civic science and policy is only a distinctive manifestation of the inherently controversial relationship between science and policy. Just as the previously mentioned European Commission study on citizen science for environmental policy has highlighted, a troubling gap exists between the potential or intended contributions of citizens generating (environmental) data and the actual policy impact that these data have. Research on the science-policy interface has emphasized the link between contribution to policy processes and (perception of) source legitimacy: ${ }^{27}$ accordingly, civic actors struggle to have their CGD recognized as a legitimate source of information, with the use of CGD in policy often being contested. ${ }^{28}$

Kimura and Kinchy discuss a number of dilemmas that might discourage authorities from considering CGD, such as the belief that science and activism should not mix, and the risk of shifting the policy focus to the wrong scale if local CGD are considered. ${ }^{29}$ Citizens and interested institutional actors thus in general have to 'justify' their data production practices through a variety of arguments targeted at any conceivable objections from recipient authorities, most especially when these data are produced by lay people. To date, however, scant attention has been devoted by scholars to such legitimization strategies and their conceivable effects. Our research question is: what legitimization strategies have interested actors adopted in order to push for the use of CGD for policy purposes? In addressing this question, we first conceptualize legitimation strategies for having CGD considered for environmental policy intervention, a conceptualization that provides a backdrop for the analysis that follows. We next present our methodology and investigate both the previous research on CGD and exemplary cases, illuminating clusters of legitimization arguments per type of CGD and intended policy use. We then offer an exploration of the conceivable effects of these strategies on targeted policy use. Finally, we draw conclusions in relation to dominant and 'minority' strategies, and outline a future research agenda. Our study seeks not merely to improve understanding of the efforts that producers and supporters of CGD have to make in order to have their data considered as legitimate scientific evidence able to inform policy making, but also to provide a resource to interested communities for developing these and further arguments deployed to attract the attention of environmental authorities.

\section{CONCEPTUALIZING CGD-BASED LEGITIMATION STRATEGIES}

\subsection{Terminological caveats}

Before detailing our main analysis, we consider it appropriate to conceptualize key terms used in this study. Thus, in this section, we characterize terms such as 'CGD' and 'legitimation strategies', and then operationalize these concepts in the analysis that follows. First, we frame 'citizen-generated data' as data produced through citizen science, sensing and other forms of civic monitoring that share the common

27. G Dunn and M Laing, 'Policy-makers Perspectives on Credibility, Relevance and Legitimacy (CRELE)' (2017) 76(C) Environmental Science \& Policy 146.

28. M Haklay, Citizen Science and Policy: A European Perspective (Woodrow Wilson International Center for Scholars, Washington DC 2015).

29. A Kimura and A Kinchy, Science by the People: Participation, Power, and the Politics of Environmental Knowledge (Rutgers University Press, London 2019). 
denominator that the data collection process is primarily carried out by volunteer citizens actively joining the initiative. ${ }^{30}$ Furthermore, these data are made available in public repositories and addressed to institutions for their consideration. ${ }^{31} \mathrm{We}$ limit our analysis to data concerning the environment, often the most controversial and contested data, compared to data on education or health services (although the COVID-19 crisis shows that epidemiological data can be highly controversial as well). Such data, in our framing, involve citizens' intention to make an argument, which excludes passive collection or even active collection limited to a private platform. Accordingly, CGD do not involve the commodification of citizens' everyday life and the normalization of surveillance, ${ }^{32}$ which would render citizens subject to problematic 'control' by authorities, making them intermediaries through the data they provide. Building etymologically on Rosenberg's definition, ${ }^{33}$ we regard 'data' as 'something given in an argument', which is essentially a form of rhetoric. Using data as a rhetorical resource thus involves a communication strategy aimed at convincing policy makers to use CGD as an alternative or in addition to official data, strategically presenting such data as 'good enough' ${ }^{34}$ for policy making.

Given this characterization of CDG, we understand 'legitimation strategies' as ways in which citizens represent their data as valid and trustworthy for policy makers as the target audience. These strategies are often mediated, involving communication media through which citizens demonstrate that their data can advance environmental policy effectively. ${ }^{35}$ In doing so, such citizens claim a space for guaranteeing their rights to participate in environmental governance in a substantial way, that is, involving an actual contribution to the debate from all concerned actors. While many researchers use the notion of 'tactic' to characterize a wide variety of forms of civic engagement, ${ }^{36}$ we opted instead for the term 'strategy', in line with observed discourses (in scholarly and empirical work). Following Certeau, we maintain that '[strategies] assume a place that can be circumscribed as proper [propre, that is, in Certeau's words, a 'spatial or institutional localization'] and thus serve as the basis for generating relations with an exterior distinct from it' ${ }^{37}$ This exterior realm to the actor making the strategy coincides with the sphere of policy makers and their reasoning that citizens have to consider when elaborating their legitimization strategies. Ironically,

30. P Rey-Mazón et al., 'Public Lab: Community-Based Approaches to Urban and Environmental Health and Justice' (2018) 24(3) Science and Engineering Ethics 971.

31. Berti Suman (n 19).

32. A Powell, 'The Mediations of Data', in J Curran and D Hesmondhalgh (eds), Media and Society, 6th edition (Bloomsbury Academic, London 2019).

33. D Rosenberg, 'Data before the Fact', in L Gitelman (ed), 'Raw Data' is an Oxymoron (The MIT Press, Cambridge MA 2013) 18.

34. J Gabrys, H Pritchard and B Barratt, 'Just Good Enough Data: Figuring Data Citizenships through Air Pollution Sensing and Data Stories' (2016) Big Data \& Society <https://journals. sagepub.com/doi/full/10.1177/2053951716679677>.

35. S Eden, 'Public Participation in Environmental Policy: Considering Scientific, Counterscientific and Non-scientific Contributions' (1996) 5(3) Public Understanding of Science 183; E Kennedy, 'When Citizen Science Meets Science Policy', in D Cavalier and E Kennedy (eds), The Rightful Place of Science: Citizen Science (Consortium for Science, Policy \& Outcomes Arizona State University 2016).

36. See for example H Jenkins, Textual Poachers: Television Fans and Participatory Culture, updated 20th anniversary edition (Routledge, London 2013); R Ralay, Tactical Media (University of Minnesota Press, Minneapolis 2009).

37. M Certeau, The Practice of Everyday Life (University of California Press, Berkeley 1984). 
citizens thus need to consider carefully in their legitimation strategies how the ways in which data are presented matter for integrating civic input into policy. In light of our conceptualization, we focus exclusively on examining uses of CGD that are questioned by authorities, which can occur at the very beginning or at a later stage of policy-making processes. Put differently, we do not discuss the issue of data quality, while acknowledging that data quality is often a precondition for being heard by policy makers.

\subsection{CGD in the context of a (perceived) breach of the social contract}

Moving to the context of our study - a gathering of XR activists in Milan, in February 2020 - the link between XR's mission and citizens' generation of (alternative) environmental data emerged. ${ }^{38} \mathrm{XR}$ attributes responsibility for the current environmental crisis primarily to public institutions that have failed to take urgently needed actions. Biodiversity loss, the increased frequency and severity of extreme weather events and the melting of glaciers are all evidence of a systemic failure, amounting to a 'breach' of the social contract. Social-contract-democracy, based on the delegation of power to appointed institutions, also implies obligations and consequent civic expectations to protect the environment ${ }^{39}$ - a contract which, according to XR, has not been fulfilled. ${ }^{40}$ Thus, XR proposes civil disobedience and mobilizes crowds to undertake non-violent protest. XR describes non-violent disobedience as 'a set of tactics and strategies using creative solutions (e.g. art) to push for a systemic change' ${ }^{41}$ These strategies strive to forge systemic change to the politico-economic systems that drive environmental damage, mostly through disruptive yet generally lawful protests. $\mathrm{XR}$ also relies on science and on scientific evidence to emphasize the urgency of the climate crisis, and to push governments to take action. We regard the production of CGD that (to different degrees) challenge the establishment as being a form of science-based, civil disobedience suggesting alternative or complementary environmental discourses. In the context of a (perceived) breach of the social contract, concerned people 'take ownership' of environmental data production in order to generate or restore 'social license' ${ }^{42}$ over environmental decisions.

\section{RESEARCH METHODOLOGY}

In this research, we investigated two main data sources with the aim of grasping multifaceted dynamics underlying CGD-based strategies. We combined a literature review

38. Training on Non-violent Resistance and Action at the Casa per la Pace, Milan, 16 February $2020<\mathrm{https}: / /$ www.casaperlapacemilano.it/en/newsletter/formazione-sullazione-diretta-nonvio lenta-insieme-a-extintion-rebellion/> accessed 17 February 2020.

39. R Kelly et al., 'Social License Through Citizen Science: A Tool for Marine Conservation' (2019) 24(1) Ecology and Society 16.

40. Speech by an XR member during a training on Non-violent Resistance and Action at the Casa per la Pace, Milan, 16 February $2020<$ https://www.casaperlapacemilano.it/en/newsletter/ formazione-sullazione-diretta-nonviolenta-insieme-a-extintion-rebellion/> accessed 17 February 2020.

41. ibid, translated into English from our notes in Italian.

42. 'Social license is a concept that reflects community views and expectations on the use and management of natural resources' in Kelly et al. (n 39) 16. 
with (secondary) case-study data. We navigated such data through an iterative process' in which findings from an initial research phase provided inputs for shaping subsequent research stages, looping between the literature and case data. Accordingly, this study is based on an exploratory analysis of the field, rather than on a systematic review.

The different steps of the analysis are summarized as follows: first, we conducted an exploratory search in the existing literature to identify how scholars discussed CGD-based legitimization strategies. Given the limited amount of material available on the topic, we focused on inquiring into targeted scholarship. Based on the preliminary literature review, we typologized legitimization themes ('clusters'). Our categorization is based on the following questions: 'What has to be legitimized?'; 'For which purposes (policy applications' spectrum)?'; 'What is being contested about the use of CGD in policy?'; 'How do citizens generating (environmental) data and their supporters try to legitimize the use of these data for policy?'; 'With respect to which discourses do interested actors seek such a legitimization?' These themes informed the case study analysis in light of the following reasons. First, we realized from our exploratory analysis that in the literature and practice surrounding CGD it is not always clear what is at stake and what citizens are fighting for (both in terms of the data at issue and the claims that these data underpin); furthermore, we considered it essential to identify which aspects of CGD were contested by relevant authorities, and which contestations stimulated the analysed strategies of persuasion; and lastly, we acknowledged the importance of focusing on qualitative discourses in order to understand how these strategies come about.

We selected cases from the aforementioned JRC inventory ${ }^{43}$ of more than 500 initiatives producing CGD for various environmental purposes on the basis of proxies, including: (1) their manifested intention to contribute to policy; (2) their actual contribution to this goal (since the inventory provides an orientation on policy uptake, we assessed this phenomenon based on further inquiry into each case); (3) the contesting by an institutional counterpart of such data; and (4) the diversity in terms of arguments adopted by the initiative/supporters thereof to have their data used for policy purposes. Ultimately, we identified 20 cases according to these four criteria. We considered these proxies to be relevant as CGD producers have an intention that is visible in these qualitative discourses of bringing forward one or more arguments. At times, CGD producers actually succeeded in realizing this intention, whereas at other times they had to deal with counter arguments from authorities, in response to which they creatively came up with persuasion strategies.

With a view to ordering the information related to the initiatives of interest, we selected key categories of analysis, ${ }^{44}$ that is, types of CGD, including: initiator(s); whether policy uptake was intended, as binary value (yes/no), ${ }^{45}$ with a specification on intended policy use(s); legitimization strategies identified; and whether a policy

43. 'An inventory of citizen science activities for environmental policies' by the European Commission Joint Research Centre <https://data.europa.eu/euodp/data/dataset/jrc-citsci10004> accessed 15 February 2020.

44. For an understanding of these categories, we refer to the descriptions contained in the 'Inventory of environmental citizen science projects' < https://data.jrc.ec.europa.eu/dataset/jrccitsci-10004/resource/8753cfeb-3495-4bb9-b2db-d151de96caa3> by the European Commission Joint Research Centre, accessed 2 March 2020.

45. It should be noted that assessing (intended and realized) policy uptake as a binary value has limitations as it may miss the nuances of a phenomenon that often is not so straightforward. 
uptake was reached, as binary value (yes/no), ${ }^{46}$ with a specification on the actual policy use(s). These categories were chosen as best illustrating the distinctive scenarios in which CGD makers advance an argument aimed at having their data used in policy making. From an 'in vivo' coding of these narratives, we extracted the main strategies each corresponding to a cluster - and the main arguments found in that cluster. Through this case study analysis, we further developed our theoretical frame, thus engaging in an iterative process from theory to the empirical data and back.

We adopted a global geographical outreach in sourcing literature and cases, but we were primarily based in a European setting due to the context of our main dataset. We also actively reached actors 'on the ground' (namely XR members in Milan, because of their proximity to our research site) in order to challenge our framing. In these discussions we focused on specific environmental issues, while always acknowledging that all these initiatives can inform a broader picture of global environmental protests.

\section{RESULTS: REVEALING SEVEN CLUSTERS OF ARGUMENTS}

Our systematic screening of the 20 cases from the inventory, selected according to the described criteria, is illustrated in Data Annex 1 - 'Table of legitimization strategies per case study, type of CGD and policy aims' where we pinpointed legitimization strategies per type of CGD and initiator, as well as by intended and actual policy uptake. In this section, we present the most relevant clusters of arguments that emerged from our screening and from subsequent analysis. Each cluster corresponds to a series of challenging questions from the authority's side and mirrors an overarching legitimization strategy. The results of our analysis are summarized in Table 1 below. In addition, in Figure 1 below, we provide a (non-exhaustive) overview of the $\operatorname{cases}^{47}$ that exemplified each

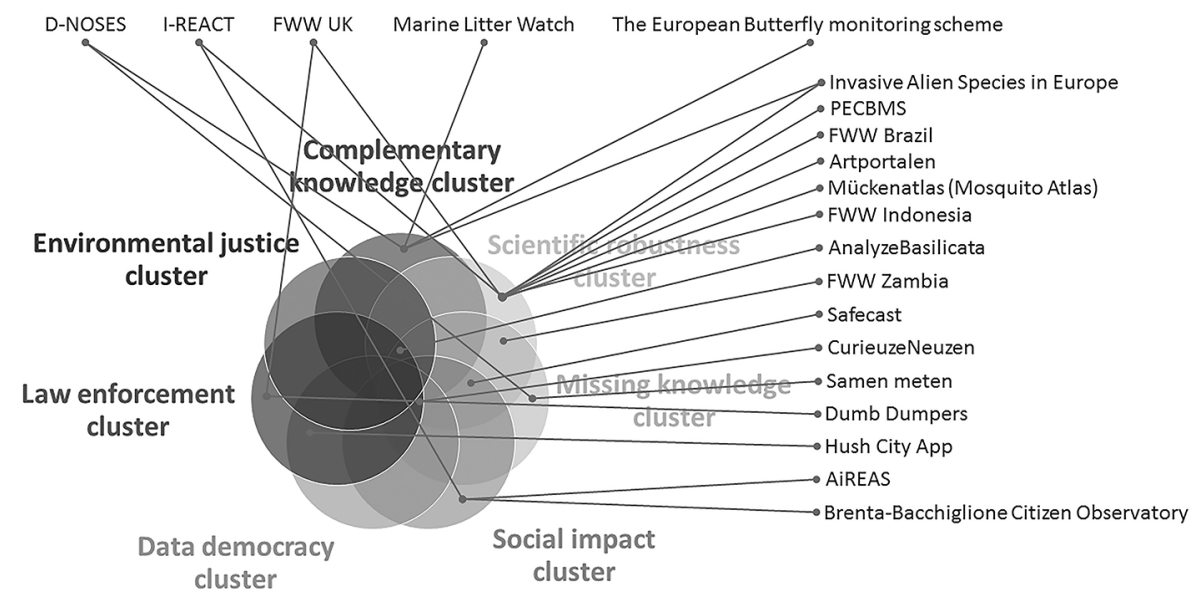

Figure 1 Clusters of legitimization strategies emerged from the case studies

46. ibid.

47. In the text that follows, we cite the case study's website only initially, when first mentioned, and not in all the subsequent instances in which we discuss the case study. 
cluster based on analysis of our findings. The correspondence between the arguments cited and the various initiatives can be verified in Data Annex 1.

\subsection{Complementary knowledge cluster}

This cluster responds to challenging questions from the side of the recipient authority, such as 'Can the data complement official monitoring to support policy actions? What is the added value to what we already have in place? Will the initiative sustain over time?'

Within the cluster, a number of arguments are used from the actors interested in contributing these data to policy aims. We summarize them as follows:

- Showing provision of data which can augment existing institutional data, for example providing spatial (uncovered areas/enhanced granularity), temporal (real time/long periods), thematic (missing topics, eventually without an existing methodology for tracking it) additional knowledge, complementing the capacity on the institutional side and thus providing an enhanced knowledge base for policy actions. Among the cases surveyed, this argument is particularly deployed by the Pan-European Common Bird Monitoring Scheme ${ }^{48}$ and by the Invasive Alien Species Europe initiative, ${ }^{49}$ whose data can be used for demonstrating support for - respectively - the implementation of EU-wide biodiversity policies and the adoption of efficient measures for controlling invasive alien species.

- Showing comparability with institutional measurement standards and the possibility of integrating indicators upon which the data are based with institutional indicators. We found this argument in the European Butterfly Monitoring Scheme initiative. ${ }^{50}$

- Showing the value of local information, particularly for understanding specific contextual issues (for example, in the case of Fresh Water Watch Brazil) ${ }^{51}$ demonstrating potential for anticipating issues and providing 'proxy measurements', that is, indication of areas where authorities may want to concentrate their limited resources (for example, in the case of the Curieuze Neuzen noise monitoring project in Flanders); ${ }^{52}$ and an underlying ability to capture 'perceptional' aspects such as citizens' risk perception (for example, in the case of Marine Litter Watch). ${ }^{53} \mathrm{We}$ found that this argument was also complemented by proving that - despite local origins - the data can indicate broader trends, for example in the case of the Distributed Network for Odour Sensing Empowerment and Sustainability (D-NOSES) initiative. ${ }^{54}$

- Showing that the community is self-sufficient, sustainable and thus able to keep monitoring and contributing to institutional knowledge over time, but also

48. The Pan-European Common Bird Monitoring Scheme <https://pecbms.info/> accessed 1 March 2020.

49. Invasive Alien Species Europe <https://easin.jrc.ec.europa.eu/easin/CitizenScience/ BecomeACitizen> accessed 12 July 2020.

50. The European Butterfly Monitoring Scheme <https://butterfly-monitoring.net/welcome> accessed 1 March 2020.

51. Fresh Water Watch Brazil <https://earthwatch.org.uk/get-involved/freshwater-watch>, $<$ https://freshwaterwatch.thewaterhub.org/blogs/eight-years-freshwater-watch-brazil $>$ accessed 1 March 2020.

52. Curieuze Neuzen <https://curieuzeneuzen.be/in-english> accessed 2 March 2020.

53. Marine Litter Watch <https://www.eea.europa.eu/themes/water/europes-seas-and-coasts/ assessments/marine-litterwatch> accessed 2 March 2020.

54. D-NOSES $<\mathrm{https}: / /$ dnoses.eu/> accessed 2 March 2020. 
emphasizing eventual dependencies of the authority on the community that monitors a specific environmental issue, as found in the case of Marine Litter Watch.

- Proving the potential of the data to be used to validate official authoritative models and that the data can contribute to co-designing methodologies to amend or improve existing models, such as in the case of Curieuze Neuzen.

\subsection{Scientific robustness cluster}

Typical questions to which this cluster responds are, among others: 'Are the data and methods used to obtain the data robust, accurate and reliable at a scientific level? Do the data fit the accuracy standards needed from a governmental perspective? Who provides these data and what might their intentions be? Can they be trusted? What do these data not show? Who is excluded or possibly underrepresented? Overall, are these data robust enough to be used to improve our scientific knowledge base?'

Among the initiatives we looked at, we identified the following approaches:

- Showing that the data are 'neutral', that is, they do not reflect any overarching political agenda. A relevant case is the Safecast post-Fukushima radiation monitoring case, ${ }^{55}$ famous for its 'pro-data approach'.

- Showing data accuracy based on the use of best monitoring techniques (which thus also depends on the funding that the initiative can access). Numerous cases seem to adopt this strategy, such as I-REACT, ${ }^{56}$ a platform aimed at monitoring climate-related environmental disasters, and the above-mentioned Invasive Alien Species Europe initiative.

- Obtaining accreditation from scientific bodies, presence in scientific journals and other forms of scientific recognition of the methods and indicators used by the initiative. Many cases adopted this strategy, among which we found the very 'reactive' Analyze Basilicata ${ }^{57}$ case aimed at monitoring oil-extraction associated with environmental contamination in southern Italy, and numerous Fresh Water Watch initiatives. Also, the Safecast case adopted technical argumentation typical of the scientific sphere and which often figures in scientific journals. ${ }^{58}$

- Showing volunteers' diverse and highly qualified expertise gained through training programmes, an argument also made by numerous biodiversity-related projects such as The Pan-European Common Bird Monitoring Scheme.

- Demonstrating strong data validation mechanisms, as found in many biodiversity projects, such as Swedish Species Observation System, Artportalen ${ }^{59}$ and the German Mosquito Atlas. ${ }^{60}$

- Showing inclusivity with appeal to a diverse and representative crowd of participants specifically responds to criticisms of biases and non-representativeness of the data. We found this demonstrated in numerous cases, including the Fresh Water Watch initiatives.

55. Safecast $<$ https://safecast.org/> accessed 2 March 2020.

56. I-REACT <https://www.i-react.eu/> accessed 26 February 2020.

57. Analyze Basilicata <http://analizebasilicata.altervista.org/blog/ $>$ and $<\mathrm{https} / / /$ covacontro. org/la-campagna/> accessed 26 February 2020.

58. J Wynn, Citizen Science in the Digital Age: Rhetoric, Science, and Public Engagement (University of Alabama Press, Tuscaloosa 2017).

59. Artportalen $<\mathrm{https}: / / \mathrm{www}$.artportalen.se/> accessed 2 March 2020.

60. The Mosquito Atlas <https://mueckenatlas.com/about/> accessed 1 March 2020. 


\subsection{Missing knowledge cluster}

The typical questions from the competent authorities to which this legitimization strategy tends to respond are: 'Why do we need (to consider the data from) citizen science and sensing initiatives when we are the actors officially appointed to take care of this problem/when this issue is outside of our policy agenda/when we do not consider this to be a problem at all? Do these CGD contradict the data currently used by us or is it filling a gap? Are such data more accurate or more fine-grained in order to convey a specific issue compared to what we currently have?'

The legitimation strategies within the cluster are summarized as follows:

- Showing that CGD are produced as a response to institutional shortcomings and are filling institutional data gaps associated with a lack of institutional resources or will to track a specific issue that nonetheless represents a matter of concern for the citizens. We found several cases using this argument, such as D-NOSES and Curieuze Neuzen.

- Challenging official measurements on a sensitive matter in relation to which the institutional (lack of) intervention is contested: the data are thus presented as substitutions of current measures or indicators by creating an alternative source of knowledge. Safecast shows this trend well.

- Showing that data provided by citizens effectively identify a need for an intervention that is not on the agenda of the competent authorities, thus operating as an 'agenda-setting' push: the data provided by citizens thus challenge the institutional decision not to address a problem, as was found in Analyze Basilicata.

- Targeting governmental needs where gaps are identified, as found in the case of Fresh Water Watch Zambia, ${ }^{61}$ whose data can be used to target shortcomings in water catchment management. In targeting institutional needs, such interested actors also have to show the comparability of their results to government data in the areas where governmental data are lacking by demonstrating reliance on the same or comparable data standards, metadata and methodologies as underpins official measurements, as was found in the air quality monitoring initiative Samen Meten. ${ }^{62}$

\subsection{Social impact cluster}

This cluster responds to questions like: 'What is the actual impact that the data from the civic initiative are having? Are they contributing in order to solve or to mitigate a problem? In case of disaster aftermath, are CGD proving to be useful informational assets for competent authorities?'

Among the cases studied, we found the following arguments, which partially reflect the surveyed literature:

- Showing that the data are responding to a public concern perceived by a group of concerned citizens affected by a specific problem, who distrust appointed authorities over how they monitor the problem, as was very visible in the Safecast case.

- Showing that the data reassured and provided actual relief for communities and for emergency actors involved in disaster response, as found in the I-REACT case.

61. Fresh Water Watch Zambia <https://earthwatch.org.uk/get-involved/freshwater-watch>, <https://earthwatch.org.uk/blogs/246-fw-update> accessed 26 February 2020.

62. Samen Meten <https://samenmeten.rivm.nl/dataportaal> accessed 12 July 2020. 
- Showing how CGD can improve the risk management system, as was the case with the Italian Brenta-Bacchiglione WeSense Citizen Observatory's ${ }^{63}$ monitoring of flood events.

- Grounding the need for consideration of CGD in a strong ideology, showing a potential for systemic, ideological and behavioural change at the city but also higher geographical level, as found in the air monitoring initiative AiREAS launched in Eindhoven. ${ }^{64}$

- Using the data as a rhetorical resource to mobilize crowds, to produce behavioural change and to influence the political debate through elections, as found in the remarkable case of Curieuze Neuzen.

\subsection{Data democracy cluster}

The types of questions these strategies seem to be responding to are, for example: 'Which perspective(s) do these data add to the debate? Who is represented by these data that is/are not represented by the data currently available to the competent institutions?'

The cases investigated use the following arguments that can be linked to this cluster:

- Showing a potential for agenda setting and discursive change that allows the civic perspective to be included in official decisions and thereby to overcome a democratic deficit (eg Curieuze Neuzen).

- Using the data as a rhetorical resource to represent the (missing or overlooked) perspective of affected citizens, while overcoming data biases owing to validation of evidence by experts, as was the case with respect to the Hush City project on quiet urban spaces. ${ }^{65}$

- Showing that the initiative is providing knowledge that cannot be sufficiently addressed by traditional representative democracy structures due to systemic issues in the functioning of appointed institutions, as in the case of Analyze Basilicata, fighting against environmental mismanagement in southern Italy.

\subsection{Law enforcement cluster}

This cluster responds to questions including 'Can these data support policy by facilitating or even enabling enforcement actions? May CGD be used to check compliance with national and international legal provisions? Can CGD serve as a source of evidence in environmental litigation?'

Among the selected cases we could identify the following specific arguments:

- Showing that the data provided can be used for facilitating governmental oversight on compliance with relevant legal provisions, such as the Water Framework Directive (Directive 2000/60/EC), as in the case of Fresh Water Watch UK, ${ }^{66}$

63. M Ferri et al. 'The Value of Citizen Science for Flood Risk Reduction: Cost-benefit Analysis of a Citizen Observatory in the Brenta-Bacchiglione Catchment' (2019) Hydrology and Earth System Sciences <https://doi.org/10.5194/hess-2019-627 >; WeSense, <https://cordis. europa.eu/project/id/308429> accessed 15 February 2020.

64. AiREAS $<$ http://www.aireas.com/ $>$ accessed 19 February 2020.

65. Hush City <http://www.opensourcesoundscapes.org/hush-city/> accessed 1 March 2020.

66. Fresh Water Watch UK <https://earthwatch.org.uk/get-involved/freshwater-watch> accessed 1 March 2020. 
or the assessment of noise levels under the Environmental Noise Directive, ${ }^{67}$ such as for the Hush City App, which was set up as a tool to empower citizens to identify and evaluate quiet areas in the city.

- Demonstrating the ability to identify and target a problem, thus facilitating institutional intervention, such as in the case of the removal of illegally dumped waste, facilitated by the Scottish initiative Dumb Dumpers. ${ }^{68}$

- Showing an actual use of the data to support enforcement actions in court where government agencies or companies are prosecuted for non-compliance with legal provisions, as occurred for Curieuze Neuzen. ${ }^{69}$

\subsection{Environmental justice cluster}

These arguments respond to questions from policy makers, such as: 'Do we have to consider these CGD because people have a right to be listened to in providing these data? If so, under what conditions? Are we legally obliged to provide feedback? Can we just ignore or acknowledge receipt but not use these data? Apart from being legitimate/legitimized, are CGD admissible for policy purposes at a legal level, that is, are these data "lawful"70?'

In the literature we found explicit recognition that CGD can be effective and useful in assisting communities in combating environmental injustice, ${ }^{71}$ addressing environmental justice $^{72}$ and climate justice ${ }^{73}$ concerns, promoting collective health and safety, ${ }^{74}$ and fostering broader social justice aims. ${ }^{75}$

Whereas in our pool of cases, instances of CGD used to make an environmental justice claim were rare, literature on the topic is abundant, suggesting a wider landscape of interventions such as supporting inclusion (and resisting the exclusion)

67. Directive 2002/49/EC.

68. Dumb Dumpers <https://www.zerowastescotland.org.uk/DumbDumpers $>$ accessed 26 February 2020.

69. S Jacobs, 'Greenpeace wil Waalse CurieuzeNeuzen' [2018] Greenpeace Belgium <https:// www.greenpeace.org/belgium/nl/persbericht/1520/greenpeace-wil-waalse-curieuzeneuzen/> (main content only available in Dutch) accessed 16 March 2020.

70. We wish to stress the important difference between the use of CGD to make practices 'lawful' (ie, in compliance with laws and regulations) and what is instead 'legitimate' based on rights (ie, having a justified, rightful role in the discussion).

71. A Kimura and A Kinchy, Science by the People: Participation, Power, and the Politics of Environmental Knowledge (Rutgers University Press, London 2019).

72. Haklay and Francis (n 2); and related blog post <https://povesham.wordpress.com/2019/ 03/16/citizen-science-2019-environmental-justice-and-community-science-a-social-movementfor-inpowerment-compliance-and-action/> accessed 12 February 2020.

73. T Mercer et al., 'Citizen Social Science for More Integrative and Effective Climate Action: A Science-Policy Perspective' (2019) Frontiers in Environmental Science <https:// doi.org/10.3389/fenvs.2019.00010>.

74. Y Abe, 'Citizen before Science: R-DAN and its Monitorial Ethic after Chernobyl', in M Fathisalout-Bollon and A Berti Suman (eds), Legal, Social and Ethical Perspectives on Health \& Technology (Lextenso Editions, Paris 2020).

75. M Haklay, 'Public Environmental Information: Understanding Requirements and Patterns of Likely Public Use' (2002) 34(1) AREA 17; S Ahme et al., 'Participatory Mapping and Foodcentred Justice in Informal Settlements in Nairobi, Kenya' (2019) 6(1) GEO: Geography and Environment <https://doi.org/10.1002/geo2.77>. 
of local $^{76}$ and Indigenous knowledge ${ }^{77}$ in environmental decisions. Other studies mention concrete cases that would deserve further inquiry, such as the strategic use of 'civic science' by environmental justice movements in Durban, South Africa, to counteract a traditional 'lack of official acknowledgement of subjective qualitative narratives' ${ }^{78}$ In a context characterized by the absence of reliable data concerning pollution impacts on human health, civic data are said to be 'opportunistically used by environmental movements' to push policy decisions. ${ }^{79}$ The use of lay knowledge in this context was 'employed to challenge the state's legitimacy imperative by invoking principles of social justice' (emphasis added). ${ }^{80}$

Among some important studies, Breen and others discuss the experience of the Public Lab community founded in response to the Deepwater Horizon oil disaster in order to 'critique existing data collection regimes' ${ }^{81}$ Wylie and others illustrate the synergy between activism and community environmental monitoring in the case of the Bucket Brigades, motivated by the 'practical need for lawyers working on an environmental justice case to get air quality data' ${ }^{82}$ Ottinger - again reflecting on the Bucket case - notes how the environmental justice movement uses civic science to contest institutional environmental standards that disregard the needs of affected communities. $^{83}$

From this evidence, we can conclude that the environmental justice argument recurs in CGD applications, especially in the United States and (partially in) South Africa. In other countries, such as those from which we speak, namely Western Europe and East Asia, these arguments seem less developed. ${ }^{84}$ Interestingly, among the cases surveyed, only one listed in our inventory, the Analyze Basilicata initiative, used 'rights discourse' to negotiate a legitimate space within the environmental decisional arena. The initiative - distinct from many other cases - explicitly used the argument that their actions were justified in light of the rights granted to

76. C Geertz, Local Knowledge: Further Essays in Interpretive Anthropology (Basic Books, New York 1983); J Scott, Seeing Like a State: How Certain Schemes to Improve the Human Condition Have Failed (Yale University Press, New Haven, CT 1999); P Rosanvallon, Good Government: Democracy beyond Elections (Harvard University Press, Cambridge, MA 2018). 77. J Gilbert and B Begbie-Clench, 'Mapping for Rights: Indigenous Peoples, Litigation and Legal Empowerment' (2018) 1 Erasmus Law Review <http://www.erasmuslawreview. nl/tijdschrift/ELR/2018/1/ELR-D-17-00015>.

78. D Scott and C Barnett, 'Something in the Air: Civic Science and Contentious Environmental Politics in Post-apartheid South Africa' (2009) 40(3) Geoforum 373.

79. ibid 373.

80. ibid.

81. J Breen et al., 'Mapping Grassroots: Geodata and the Structure of Community-led Open Environmental Science' (2015) 14(3) ACME: An International E-Journal for Critical Geographies 850 .

82. SA Wylie, K Jalbert, S Dosemagen and M Ratto, 'Institutions for Civic Technoscience: How Critical Making is Transforming Environmental Research' (2014) 30(2) The Information Society 181 .

83. G Ottinger, 'Buckets of Resistance: Standards and the Effectiveness of Citizen Science' (2010) 35(2) Science, Technology, \& Human Values 259.

84. Nonetheless, research in this area should grow in the coming years, for example starting from the ongoing Dutch Research Council NWO-funded Rubicon project titled 'SENSJUS - Citizen Sensing as a source of evidence in environmental justice litigation and as a tool for environmental mediation', hosted at the European Commission Joint Research Centre, Ispra (Italy). 
concerned citizens by the Aarhus Convention and by the national (in this case, Italian) provisions implementing it. ${ }^{85}$

Turning specifically to the EU legal field, in the context of the Directive on Public Access to Environmental Information, ${ }^{86}$ the European Commission released a 'Citizen's guide to access to justice in environmental matters' ${ }^{87}$ and a 'Notice on Access to Justice in Environmental Matters' ${ }^{88}$ with the aim of providing guidance on how individuals and their associations can challenge decisions, acts and omissions by public authorities related to EU environmental law before national courts. ${ }^{89}$ In the United States, some years before, the Environmental Law Institute had also released A Citizen's Guide to Using Federal Environmental Laws to Secure Environmental Justice..$^{90}$ Both documents express institutional attention to citizens' entitlement to have their voices heard on environmental matters. One form of exercising this entitlement can be through the provision of CGD, when such data expose the perpetration of environmental misinformation and injustice.

\section{DISCUSSION: IDENTIFYING TWO SIDES OF THE SAME COIN}

\subsection{Disentangling patterns throughout the clusters}

The above case studies are now discussed in order to consider the following aspects of our research project: who make(s) the argument; for which type of CGD; what kind of discourse is used and for which type of policy use; and lastly, what (conceivable) effect might such strategies have?

The 'Complementary knowledge cluster' comes from both institutionally and NGO-led initiatives. The data range from environmental issues to biodiversity, and operate at different geographical scales, but have the common trait of being produced by initiatives that adopt a relatively 'cooperative' discourse. In terms of intended policy uptake, the types of policy applications targeted by this strategy are very diverse, with a prevalence of problem definition, policy implementation and policy monitoring. The majority of the cases that we identified as using this strategy seem to have managed to target policy needs through their data and effectively to have increased the knowledge base available for the targeted authorities. ${ }^{91}$

85. A Berti Suman, 'Civic Resistance to Environmental Failures from the South of the North: The Analyze Basilicata Initiative' (2018) Data Activism Blog <https://data-activism.net/2018/12/civicresistance-to-environmental-failures-from-the-south-of-the-north-the-analyzebasilicata-initiative/> accessed 3 March 2020; G Santoriello, Colonia Basilicata (COVA Contro 2019).

86. Directive 2003/4/EC.

87. European Commission, Citizen's Guide to Access to Justice in Environmental Matters (Publications Office of the European Union, Luxembourg 2018).

88. Commission Notice on Access to Justice in Environmental Matters (18 August 2017) 2017/C 275/01. The notice has been inspired by relevant decisions of the EU Court of Justice on controversies between public authorities of the Member States and individuals/associations.

89. ibid, especially 7-16.

90. Environmental Law Institute, ‘A Citizen's Guide to Using Federal Environmental Laws to Secure Environmental Justice’ (2002) EPA <https://www.epa.gov/sites/production/files/201502/documents/citizen_guide_ej.pdf $>$ accessed 18 September 2019.

91. See Data Annex 1 'Table of legitimization strategies per case study, type of CGD and policy aims'. 
The 'Scientific robustness cluster', overall, is prevalent in institutionally-oriented (often biodiversity) projects, which also use the argument based on expert validation of results and alignment with official indicators. This argument is missing in more grassroots-driven projects that instead strive to obtain and show scientific recognition of independent, non-governmental certification bodies, as witnessed in the Safecast and Analyze Basilicata initiatives. Biodiversity projects also tend to show reliance upon advanced validation techniques, often also relying on the support of experts, such as in the Swedish Species Observation System, Artportalen. Conversely, more distrusting projects push to have their 'neutrality' and impartial approach recognized, as found in the case of Safecast. Openness seems to be a key assurance for data quality for all types of data. ${ }^{92}$ In terms of policy uptake, the policy purposes span policy monitoring, implementation and early warning. ${ }^{93}$ It appears that this strategy is essential for actual policy uptake. ${ }^{94}$

Our analysis of the cases adopting the 'Missing knowledge cluster' shows that these CGD often come from NGO- and community-driven initiatives targeting a concrete problem and specific matter of concern for the participants, such as the lack of official information on the status of a polluted site. The intended policy uses of these types of data are often early-warning and problem definition, in general calling for institutional attention to a more or less intentionally overlooked or ignored environmental problem through the introduction of missing knowledge. We found that in some (rare) cases these uses are achieved, yet that in general this did not occur or at least was not plainly recognized. ${ }^{95}$

Moreover, we found a 'Social impact cluster' for CGD targeting environmental risks that are pressing in terms of public concern and controversy. These data often come from NGO- or community-led initiatives aimed at responding to institutional failures or filling data gaps and thereby bypassing or substituting the governmental response. In terms of intended policy applications, the uses to which these data are targeted are diverse, and include policy monitoring, policy implementation and early-warning. Some of these goals are achieved, for example when the initiative obtains institutional attention by demonstrating its potential to mobilize crowds, as described for the Curieuze Neuzen case. However, often the policy linkages are less evident, as when the initiative strives to show that it does not need policy intervention, as found in the Safecast experience.

The 'Data democracy cluster' addresses data on environmental issues that are perceived to be particularly controversial, supplied by initiatives that are often NGO- or community-led. The initiatives producing these data often push for a substantial, systemic change not only in respect of the consideration of data by authorities but also in respect of the types of actors entitled to provide these data, legitimizing their contribution based on the need to 'democratize' the knowledge base used for policy decisions, such as in the case of the Hush City project on quiet urban spaces. In terms of intended contribution to policy, these data are often targeted at problem definition and early-warning. ${ }^{96}$

92. ibid.

93. ibid, especially look at 'Intended policy use(s)' column.

94. ibid, especially look at 'Policy uptake reached?' column.

95. ibid.

96. ibid, especially look at 'Intended policy use(s)' column. 
Among the initiatives using arguments belonging to a 'Legal enforcement cluster', the data were very diverse, ranging from the more institutionalized (academia/institutionally-led) to the more NGO- and community-driven. Nonetheless, these initiatives seem to have in common the fact that they target the risk of non-compliance with environmental legislation (at national and/or supra-national levels). Consequently, they tend to focus on a specific environmental problem. In terms of intended policy use, these are often aimed at problem definition, early-warning (of an incidence of non-compliance, for example) and policy implementation. Overall, these initiatives tend to achieve these aims, although some uses, such as the deployment of these strategies in courts, are still undeveloped and hard to find in current CGD applications. ${ }^{97}$

Despite the increasing level of attention paid by scholarly literature to CGD's potential for environmental justice, ${ }^{98}$ 'grassroots' CGD practitioners have still not sufficiently explored or, at least, used the rights-based strategy, the 'Environmental justice cluster', which we found in only one case. ${ }^{99}$ Another line of argumentation falling within this cluster could be that of lobbying for legal recognition through national legislative intervention, which would present a strong argument for being considered 'legitimate'. Although not included in our study inventory, we are aware of an example from Ecuador where, after successful experiences of communitybased monitoring performed in the Ecuadorian Amazon, the practice in question was officially endorsed in a legal text: the 'Amazon Law' of 2018 (Ley Orgánica Especial de la Circunscripción Territorial Especial Amazónica). ${ }^{100}$ Without deeper empirical inquiry, however, we cannot determine whether this rare use of an environmental justice discourse depends on the fact that laws granting rights to citizens are seen as 'obscure' and difficult to master by the CGD-making communities or whether this paucity of instances depends on these actors and communities not having realized the potential that underlies such legislative provisions.

\subsection{Two overarching threads: a rightful and an effective source for policy}

Two threads - partially overlapping - can be identified running through the clusters. The first emphasizes the argument that CGD is trustworthy, effective and can lead to better environmental policy, as illustrated in Figure 2 below. The second reflects the overarching idea that authorities could/should be regarded as having an obligation to listen to citizens' voices by considering their CGD, as Figure 3 below shows.

The 'Data democracy' and 'Environmental justice' clusters (a minority) would belong to the first thread, while all the others including the 'Complementary' and 'Missing knowledge' clusters (which are also majoritarian) to the latter.

97. ibid, especially look at 'Legitimization strategies' column.

98. Berti Suman (n 19); Haklay and Francis (n 2); Balestrini (n 21).

99. The Analyze Basilicata case, see Data Annex 1 'Table of legitimization strategies per case study, type of CGD and policy aims'.

100. 'Artículo 58. Monitoreo ambiental comunitario. En la Circunscripción se implementarán mecanismos de monitoreo ambiental comunitario, en coordinación y según las disposiciones y requisitos que la autoridad ambiental nacional determine para el efecto.' Unofficial translation by the authors from Spanish: 'Article 58. Community-based environmental monitoring. In the Circumscription, community-based environmental monitoring mechanisms will be implemented, in coordination and according to the dispositions and requirements set by the national environmental authority for the purpose.' 


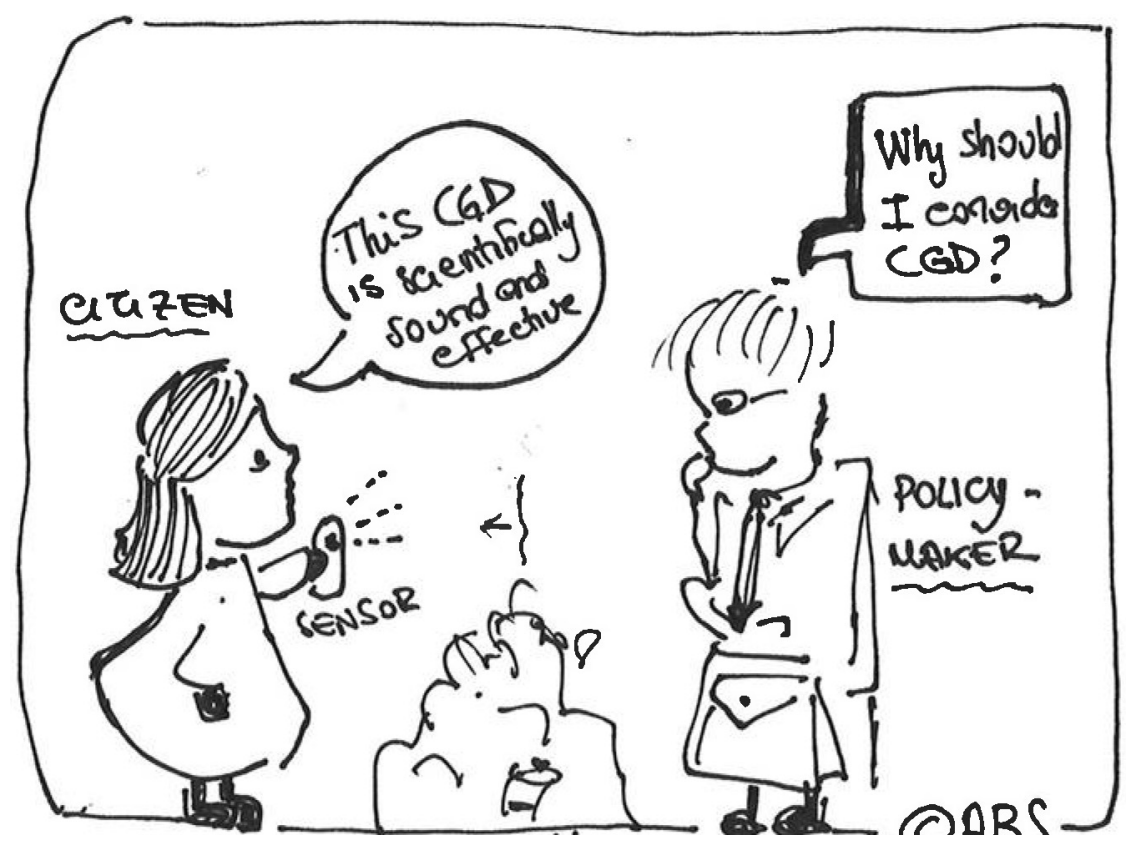

Figure 2 Illustration of the rights-based/democracy thread [drawing by Anna Berti Suman]

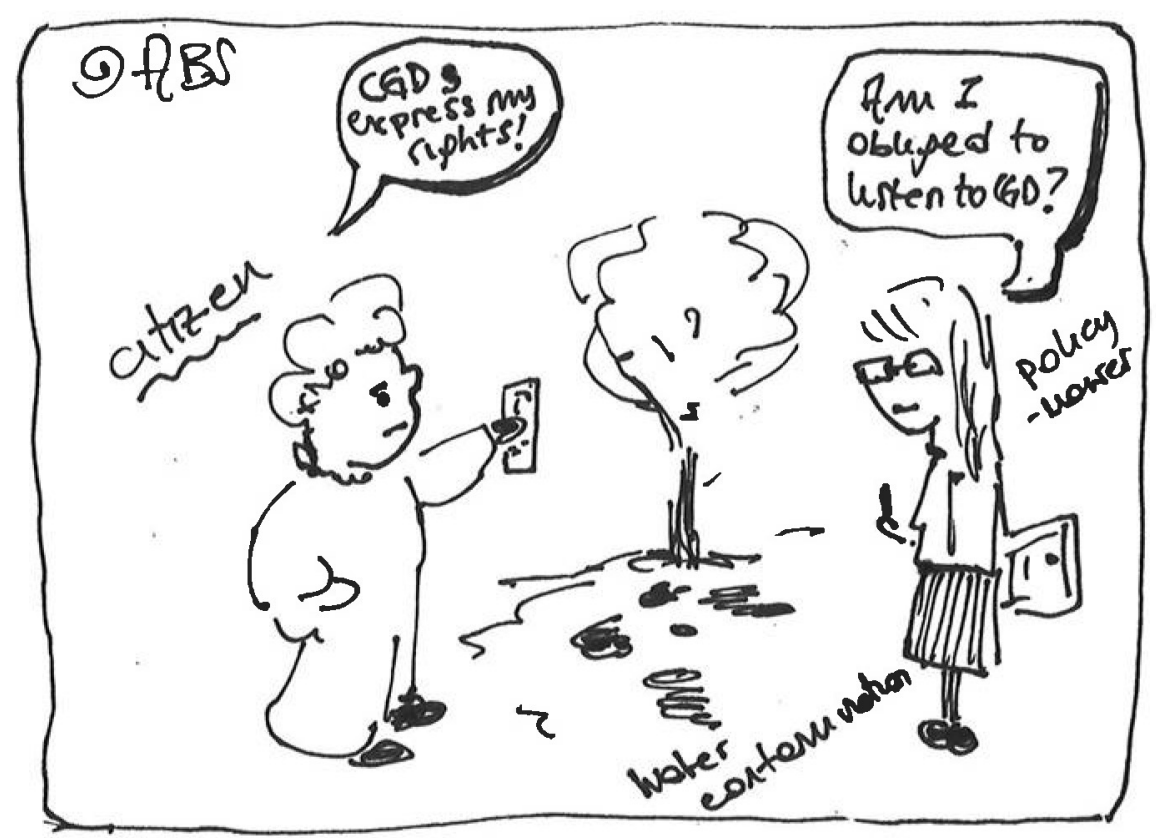

Figure 3 Illustration of the CGD's soundness thread [drawing by Anna Berti Suman] 
These trends are in part mirrored in the academic ${ }^{101}$ and grey ${ }^{102}$ literature, where arguments such as the claim that CGD are scientifically robust have been widely advanced. Grey literature ${ }^{103}$ has also stressed how forms of CGD's production can contribute to, among other policy purposes, the variety of policy purposes. Doctrinal reflections in the field of environmental risk governance ${ }^{104}$ have extensively emphasized the contributory potential of lay knowledge and the importance of including a variety of perspectives in dealing with complex environmental issues. Abe, discussing a civic radiation monitoring network that developed after Chernobyl, describes how the initiative arose 'in the absence of publicly available information about radioactivity in the wake of the disaster', ${ }^{105}$ and was thus able to contribute missing environmental knowledge. Furthermore, academic ${ }^{106}$ and grey ${ }^{107}$ literature emphasizes the role of CGD as a precious (and innovative) resource for societal actors including for governments. Berti Suman also noted that CGD can make visible 'politically masked risks', thus contributing to societal awareness and to the determination to act. ${ }^{108}$ Göbel and others ${ }^{109}$ contributed to this discourse by highlighting how CGD can influence social dynamics without involving policy-making action.

A flourishing literature has also depicted CGD in its connection to data democracy and environmental justice claims. Abe, quoting Fujita, argues that CGD are 'a democratic resource for empowering ordinary people'. ${ }^{110}$ From a social justice perspective, Kimura and Kinchy affirm that 'transformative citizen science' can help marginalized communities to be heard and can produce knowledge from points of view that historically have been excluded from scientific institutions. ${ }^{111}$ Yet, we are aware that this inclusion can occur only when such communities have access to the necessary resources and can develop the necessary capacity to enter the scientific arena. Beraldo and Milan describe the 'contentious politics of data' represented by CGD-production

101. Berti Suman (n 19).

102. Bio Innovation Service, Citizen Science for Environmental Policy: Development of an EU-wide Inventory and Analysis of Selected Practices (European Commission Joint Research Centre 2018).

103. ibid.

104. O Renn, A Klinke and M van Asselt, 'Adaptive and Integrative Governance on Risk and Uncertainty’ (2011) 15(3) Journal of Risk Research 273; O Renn, Risk Governance: Coping With Uncertainty in a Complex World (Earthscan, London 2008); U Beck, Risk Society: Towards a New Modernity (Sage, London 1992).

105. Abe (n 74).

106. G Misuraca and G Pasi, 'Landscaping Digital Social Innovation in the EU: Structuring the Evidence and Nurturing the Science and Policy Debate towards a Renewed Agenda for Social Change' (2019) Government Information Quarterly.

107. Bio Innovation Service, 'Citizen Science for Environmental Policy: Development of an EU-wide Inventory and Analysis of Selected Practices' (European Commission, Joint Research Centre 2018).

108. A Berti Suman, 'Making Visible Politically Masked Risks: The Haze Case of Bottom-up Data Visualization' in H Kennedy and M Engebretsen (eds) Data Visualization in Society. The Relationships between Graphs, Charts, Maps and Meanings, Feelings, Engagement (Amsterdam University Press, Amsterdam 2020).

109. C Göbel et al., "How Does Citizen Science "Do" Governance? Reflections from the DITOs Project' (2019) 4(1) Citizen Science: Theory and Practice.

110. Abe (n 74).

111. A Kimura and A Kinchy, Science by the People: Participation, Power, and the Politics of Environmental Knowledge (Rutgers University Press, London 2019). 
as tactics in the context of political struggles. ${ }^{112}$ Haklay and Francis note that institutional recognition of forms of CGD can instil environmental justice in policy and decision making. ${ }^{113}$ Lastly, Craglia and Shanley advance a powerful argument, that 'opening up the bases of decisions by government agencies and private corporations [to CGD is, overall,] a necessary development to foster a vibrant, open and informed society ${ }^{114}$ and - we add - a democratic and environmentally just society.

A cluster that could be considered as bridging these two main threads is the one revolving around environmental compliance. Arguably, through using CGD to check and to promote compliance with environmental norms, a contribution is provided both to the effectiveness of policies and to the advancement of environmental justice and democratic claims. The extant literature appears to acknowledge this twofold potential. Berti Suman notes that deeper scrutiny is needed of the grounds upon which CGD can be used in courts in environmental litigation, a scrutiny that is inherently very context-dependent. ${ }^{15}$ Abe stresses the role of CGD in making governments environmentally accountable. ${ }^{116}$ Also, grey literature both from the EU ${ }^{117}$ and the United States ${ }^{118}$ has widely recognized the value of CGD for environmental compliance assurance. Accordingly, CGD could be a resource used to monitor compliance with legal norms and to aid enforcement actions where such norms are violated.

\section{CONCLUDING REFLECTIONS AND FUTURE RESEARCH DIRECTIONS}

In Table 1 below we provide a summary of the clusters of arguments that emerged from our case study analysis, guided by relevant literature and orienting criteria. Clusters are ordered from the most prevalent, the 'Complementary knowledge cluster' to the least prevalent, that is, the 'Environmental justice cluster'.

Two threads, as noted above, emerged through the clusters, entailing two complementary arguments, namely that listening to CGD is a governmental obligation in light of citizens' rights and entitlements, and that CGD, regardless of any state's obligation

112. D Beraldo and S Milan, 'From Data Politics to the Contentious Politics of Data' (2019)

6(2) Big Data \& Society.

113. Haklay and Francis (n 2) 10.

114. M Craglia and L Shanley, 'Data Democracy - Increased Supply of Geospatial Information and Expanded Participatory Processes in the Production of Data' (2015) 8(9) International Journal of Digital Earth Q 690.

115. ibid.

116. Abe (n 74).

117. COM(2017)312 'Actions to Streamline Environmental Reporting'; actions on environmental compliance assurance from the European Commission can be found at $<\mathrm{https} / / / \mathrm{ec}$. europa.eu/environment/legal/compliance_en.htm>; documentation on citizen engagement in environmental compliance assurance can be found at $<\mathrm{https}$ ://ec.europa.eu/environment/legal/ pdf/2019-A7-W3-DOC2-Draft-Complaint-Documentation42.pdf> accessed 3 March 2020.

118. Emmett Environmental Law and Policy Clinic, 'Using Citizen Science Evidence in Litigation - DRAFT' [2019] Harvard Law School <https://citizenscienceguide.com/sites/default/ files/images/Supplement\%202\%20Using\%20Citizen\%20Science\%20Data\%20in\%20Litigation \%20March\%202019.pdf>; B Smith, 'Agency Liability Stemming from Citizen-Generated Data' (2014) Wilson Center - Policy Memo Series vol $3<$ https://www.wilsoncenter.org/ sites/default/files/AgencyLiability_final.pdf>; Wyeth et al. (n 18); J McElfish, J Pendergrass and T Fox, Clearing the Path: Citizen Science and Public Decision Making in the United States (The Wilson Center, Washington DC 2016). 
Table 1 Summary of clusters, in order of decreasing presence

\begin{tabular}{|c|c|}
\hline Cluster name & Cluster description \\
\hline $\begin{array}{l}\text { Complementary knowledge } \\
\text { cluster }\end{array}$ & $\begin{array}{l}\text { Aims to show that CGD can provide unique local knowledge at } \\
\text { spatial scale or granularity that is not otherwise available } \\
\text { and/or allowing coverage over extensive time, and that the } \\
\text { initiative is well suited to function and can be sustained in the } \\
\text { medium and long term. }\end{array}$ \\
\hline Scientific robustness cluster & $\begin{array}{l}\text { Aims to show the scientific credibility and accuracy of the data } \\
\text { and representativeness of the measurements provided by the } \\
\text { citizens. }\end{array}$ \\
\hline Missing knowledge cluster & $\begin{array}{l}\text { Aims at demonstrating that the CGD can fill institutional gaps } \\
\text { and challenge institutional decisions not to monitor certain } \\
\text { environmental aspects or challenge existing data that over- } \\
\text { look specific issues. }\end{array}$ \\
\hline Social impact cluster & $\begin{array}{l}\text { Seeks to show that the initiative is actually relevant for the } \\
\text { (affected or larger) society. }\end{array}$ \\
\hline Data democracy cluster & $\begin{array}{l}\text { Seeks to demonstrate that the CGD target epistemological } \\
\text { injustice by bringing in missing perspectives and voices. }\end{array}$ \\
\hline Law enforcement cluster & $\begin{array}{l}\text { Aims at showing that CGD can support compliance assurance } \\
\text { actions by authorities, fostering respect for legal obligations. }\end{array}$ \\
\hline Environmental justice cluster & $\begin{array}{l}\text { Centring on the overarching argument that taking CGD into } \\
\text { account can foster environmental justice and is legitimate as } \\
\text { an expression of human environmental rights. }\end{array}$ \\
\hline
\end{tabular}

in that sense, is ultimately beneficial for policy processes and outputs. The 'Law enforcement cluster' illustrates well how these two threads may overlap. Furthermore, beyond this (artificial) categorization, we emphasize that - despite reacting to different challenging questions - all the clusters share the common denominator of being communication strategies aimed at justifying the role of citizens in providing (environmental) data for policy purposes, which we identify as the overarching goal. Through a review of actual legitimization strategies, we have argued, indeed, that concerned actors seek to demonstrate that they have a legitimate stance in producing data that support their claims to environmental justice.

Yet, in spite of flourishing recognition in the relevant literature, it seems that citizens producing environmental data to substantiate their claims are rarely adopting a democracy-based or, even less, a rights-based discourse. ${ }^{119}$ This discrepancy might suggest a possible mismatch between current (environmental law) scholarship and what is occurring 'on the ground'. The most used and effective strategies instead include demonstrating the scientific strength and contributory potential of CGD. ${ }^{120}$ This emphasis might reflect a variety of reasons but we hypothesize two specific explanations: first, a significant lack of capacity in the civic actors to 'use' their legal entitlements strategically (either because they do not know them properly or because they are not experienced in exercising them); and second, an intrinsic lack of trust in the legal data regarded as a manifestation of an (unjust) political establishment.

119. See Data Annex 1 'Table of legitimization strategies per case study, type of CGD and policy aims', especially look at the 'Legitimization strategies' column.

120. ibid. 
These conceivable reasons, suggested based on our analysis, should be verified through further empirical research. We can say - however - that we consider this result to be problematic since the generation and sharing of (environmental) data by citizens amounts to more than merely supplying robust data to support science or policy; it is also a proactive claim for social ideals and (environmental) justice. Furthermore, legitimizing forms of CGD-making on the basis of human (environmental) rights could guarantee that citizens can freely perform their monitoring practices without fearing any legal consequences. ${ }^{121}$ Indeed, legitimizing CGD based on legal entitlements can facilitate engagement and, in extreme contexts, even safeguard the participating citizens against adverse effects of their action (eg any legal prosecution).

By investigating and systematizing approaches to legitimizing the use of CGD and highlighting gaps, our study has sought to improve understanding of the efforts that producers and supporters of CGD have to make in order to have their evidence considered by policy makers and regulators. We hope to see advocating for a specific environmental justice focus included in future discussions, case studies and scholarly reflections, since such a focus has often been underrepresented in citizen science and sensing research.

We think that our study has also contributed to ongoing research on policy processes and source legitimacy. ${ }^{122}$ Strategies entailing contestation of the final decision in environmental matters can also tackle the source upon which the decision is based, especially in cases of controversial environmental policies. In our contribution, we have gone beyond existing studies on traditional scientific knowledge as a legitimate base for policy to focus on lay knowledge captured in CGD as a resource for institutional decisions on contested environmental issues. In doing so, we enrich a growing body of grey and academic literature that has highlighted the potential of unconventional sources of knowledge for (environmental) policy. ${ }^{123}$

There are limitations in this research. Most fundamentally, our investigation does not encompass (a very much needed) empirical analysis of the effects of specific legitimization strategies on the actual policy uptake of CGD. Accordingly, we could only make unverified assumptions about the larger empirical effects. Furthermore, generalizing from the legitimization strategies that we identified can be particularly difficult as these strategies take place in specific political, social, cultural and historical contexts. In addition, we found that terminological boundaries between categories of data types, policy uses and legitimization strategies are particularly blurred and difficult to systematize, making it challenging to ensure that a term is used with a consistent meaning by different actors. Labels are necessarily relative and contextual, and thus our analysis can necessarily be interpreted otherwise. Furthermore, our labels

121. Producing CGD can expose the citizens to considerable legal risks, as described extensively in A Berti Suman, Sensing the Risk: In Search of the Factors Contributing to the Policy Uptake of Citizen Sensing (Doctoral Thesis, Tilburg University, Tilburg 2020) and specifically within the 'Case Insight - The Wyoming Case of Criminalization of the Citizen Scientists' 97. 122. Dunn and Laing (n 27).

123. L Shanley et al., 'Policy Perspectives on Citizen Science and Crowdsourcing: A Special Issue' (2019) 4(1) Citizen Science: Theory and Practice; A Turbé et al. 'Understanding the Citizen Science Landscape for European Environmental Policy: An Assessment and Recommendations' (2019) 4(1) Citizen Science: Theory and Practice; Bio Innovation Service, 'Citizen Science for Environmental Policy: Development of an EU-wide Inventory and Analysis of Selected Practices' (European Commission, Joint Research Centre 2018); A Bonn et al. 'Citizen Science to Foster Innovation in Open Science, Society and Policy' in S Hecker et al. (eds), Citizen Science (UCL Press, London 2018). 
are artificial in that other overarching categorizations of the clusters could have been conceived and applied, such as 'antagonistic' or 'cooperative' arguments. Moreover, our knowledge of legitimization strategies is limited to what the citizens' initiative shared online or to what has been published in academic or grey literature. Lastly, as these initiatives take place in different countries where local idioms are used to communicate the groups' arguments, our analysis has had to contend with the added difficulties of ensuring accurate translation. That being said, we could typologize legitimization strategies that illustrate pathways of success in a qualitative way, albeit that future research should systematically screen a larger number of cases and strategies, and possible policy uptake outcomes. There is also a need for more finegrained project evaluations, which will require many more case studies for a reliable quantitative assessment.

Deeper case knowledge scrutiny is also indispensable for grasping important trends such as how time and past experience matter as a strategic argument, as currently witnessed with the Safecast initiative presenting itself to institutions as a legitimate source of information on the COVID-19 spread, based on the initiative's proven ability to respond to the Fukushima disaster. ${ }^{124}$ Also, aspects of CGD such as geographical dimensions, contextual features and administrative levels targeted, among various factors, could influence the effectiveness of a legitimization strategy. The presence of 'mediators' between the citizen scientists making a claim and the recipient authorities could also have an influence. Also, it seems relevant to inquire whether the fact that the initiative responds to an environmental stress or instead to a shock matters for policy uptake. Furthermore, the level of scientific uncertainty over an environmental matter can influence the willingness of policy makers to listen to CGD.

However, a success factor in one case is not necessarily relevant to another context. Future research should therefore ideally assess the relevance of different geographical contexts, the temporal evolution of the strategies and other contextual features. Researchers might also be interested in inquiring into the legitimization of using passively collected CGD (ie those data produced by citizens without their choice to provide data to make a claim) for science and policy purposes. Lastly, further inquiry will be valuable for answering the fundamental question as to why environmental rights and democracy-based arguments are currently largely overlooked by communities supplying CGD to policy makers. Considering that such arguments could be powerful in grounding CGD's legitimacy for environmental policy, we encourage researchers and practitioners alike to explore and promote these discourses.

124. Azby Brown from Safecast speaking at the SHARE Webinar: 'Lessons We Are Learning from the COVID-19 Pandemic for Radiological Risk Communication', 16 March $2020<\mathrm{https}$ // www.ssh-share.eu/webinar/> and <https://safecast.org/covid19> accessed 26 March 2020. 


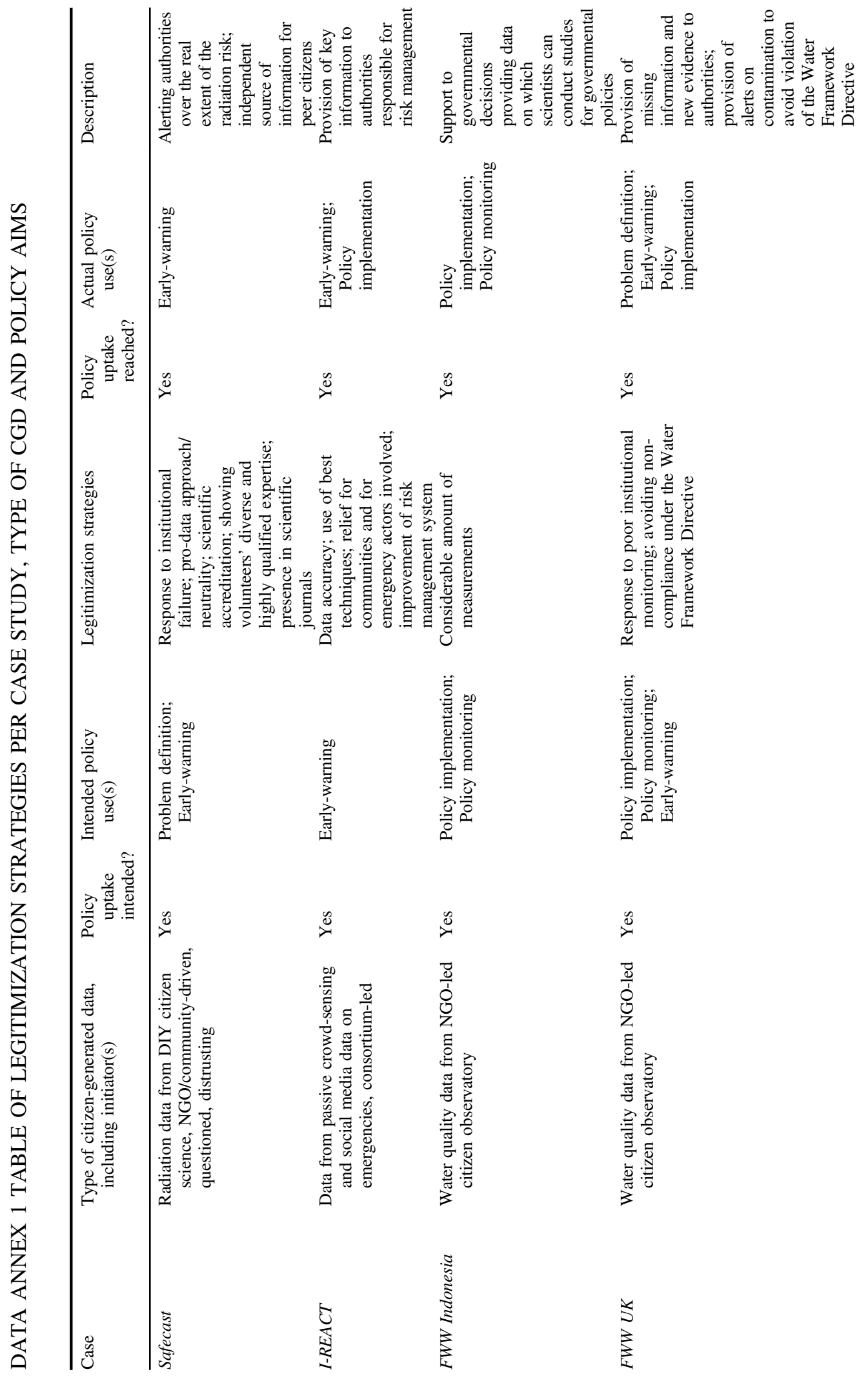




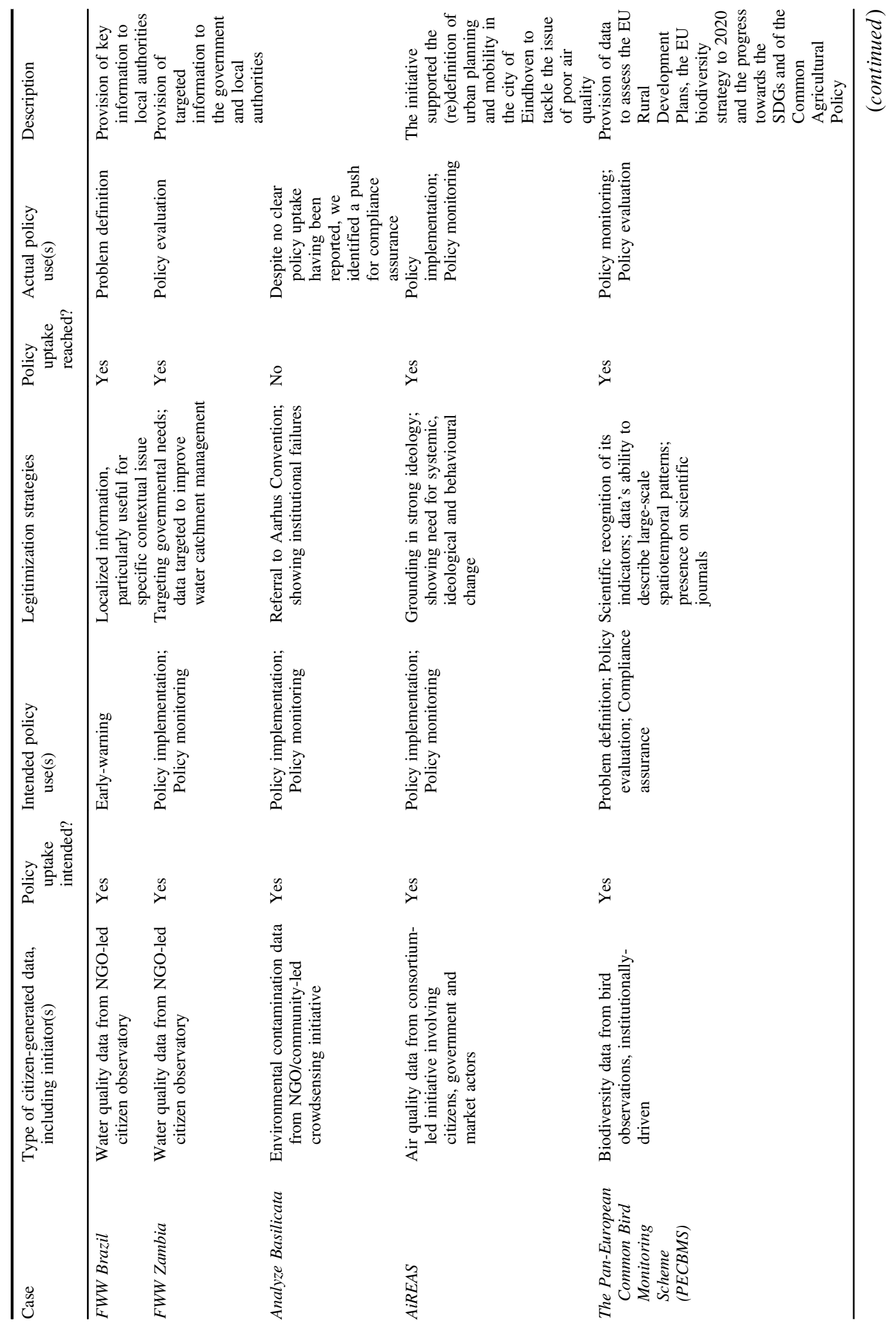




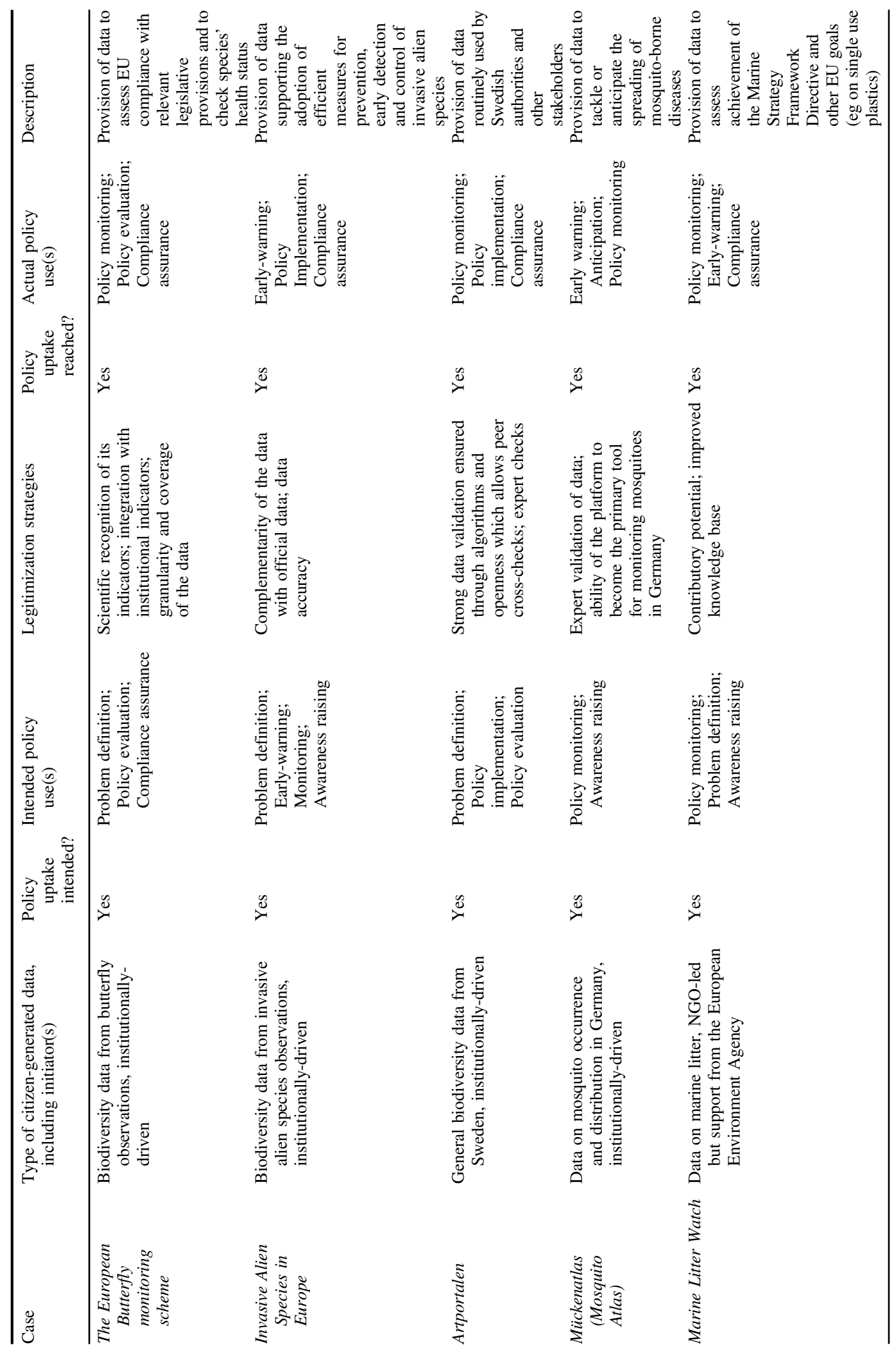




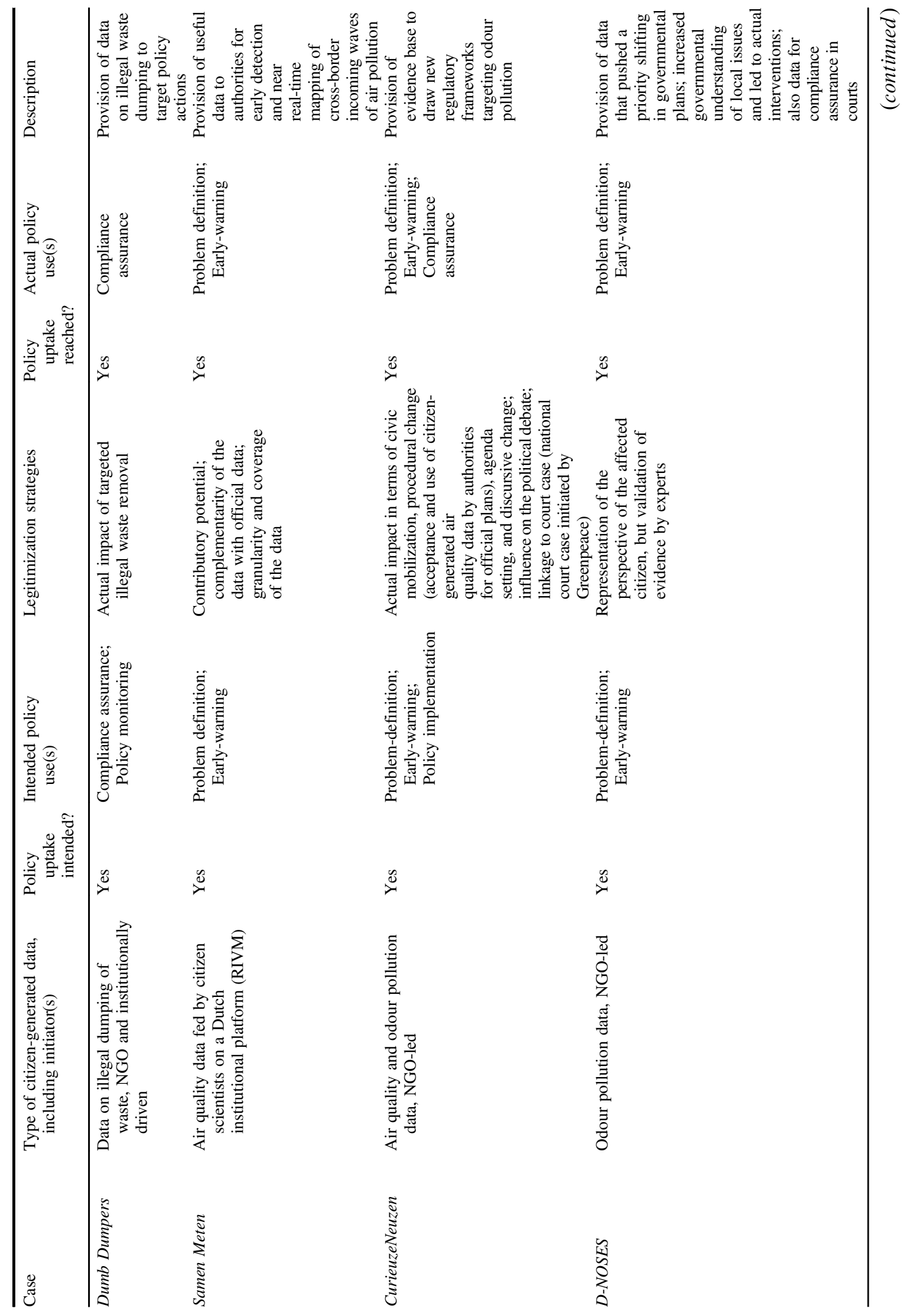




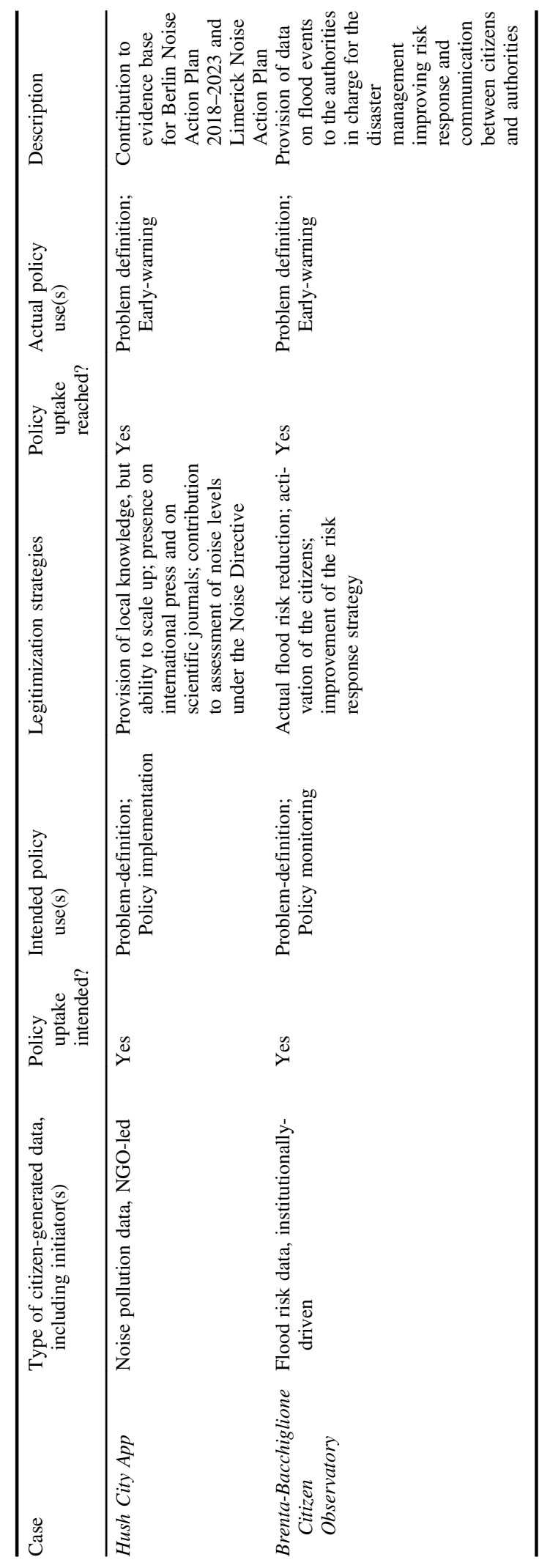

